\title{
Arsenic Adsorption on Iron-Modified Montmorillonite: Kinetic Equilibrium and Surface Complexes
}

\author{
Analia Iriel, ${ }^{1,2}$ Jose L. Marco-Brown, ${ }^{3, *}$ Maja Diljkan, ${ }^{2}$ María Alcira Trinelli, ${ }^{4,5}$ \\ María dos Santos Afonso, ${ }^{6,7}$ and Alicia Fernández Cirelli ${ }^{1,2}$

\begin{abstract}
${ }^{1}$ Animal Production Research Institute (INPAVUBA-CONICET), Faculty of Veterinary Science, University of Buenos Aires, Argentina. ${ }^{2}$ Institute for Transdisciplinary Water Research (CETAVUBA), Faculty of Veterinary Science, University of Buenos Aires, Argentina.

${ }^{3}$ Institute of Environmental Research and Engineering (IIIA), CONICET, UNSAM, University of San Martín, Buenos Aires, Argentina.

${ }^{4}$ Institute of Basic, Applied and Environmental Geosciences of Buenos Aires (IGEBA/UBA-CONICET), Buenos Aires, Argentina.

${ }^{6}$ Department of Inorganic, Analytical and Physical Chemistry (DQIAQF), Faculty of Exact and Natural Sciences (FCEN), University of Buenos Aires (UBA), Buenos Aires, Argentina.

${ }^{7}$ Institute of Chemical Physics of Materials, Environment and Energy (INQUIMAE/CONICET-UBA), University of Buenos Aires,
\end{abstract} \\ ${ }^{5}$ Geological Science Department, Faculty of Exact and Natural Sciences (FCEN), University of Buenos Aires (UBA), Buenos Aires, Argentina.
} Buenos Aires, Argentina.

Received: May 20, $2019 \quad$ Accepted in revised form: September 5, 2019

\begin{abstract}
$\mathrm{As}(\mathrm{V})$ adsorption mechanisms on an iron-modified montmorillonite (Fe-Mt) were studied by analysis from kinetic and equilibrium perspectives, and applicability of Fe-Mt for $\mathrm{As}(\mathrm{V})$ removal from groundwater was evaluated. Iron-modified montmorillonite was characterized by Small Angle X-Ray Scattering (SAXS), Wide Angle X-Ray Scattering (WAXS) and scanning electron microscopy technique and an excellent performance for $\mathrm{As}(\mathrm{V})$ removal, even at neutral and basic $\mathrm{pH}$ values and high conductivity conditions, was determined. Moreover, $\mathrm{As}(\mathrm{V})$ adsorption was higher with the increasing of ionic strength of the solution. Both Langmuir and Freundlich models provided a suitable fit to the experimental data, and the maxima adsorption capacity was $6.3 \mathrm{~g} / \mathrm{kg}$. Kinetic studies indicated that about $99 \%$ of $\mathrm{As}(\mathrm{V})$ was removed in the first $30 \mathrm{~min}$ of time from a starting concentration of $3 \mathrm{mg} / \mathrm{L}$ following a pseudo-second order kinetic. Formation of inner-sphere complexes of $\mathrm{As}(\mathrm{V})$ at the surface of $\mathrm{Fe}-\mathrm{Mt}$ was stated by evaluation of $\mathrm{As}(\mathrm{V})$ adsorption in the presence of $\mathrm{Cl}^{-}, \mathrm{NO}_{3}^{-}$, and $\mathrm{PO}_{4}{ }^{3-}$ ions and of the zeta potential versus $\mathrm{pH}$ curves.
\end{abstract}

Keywords: adsorption; arsenic; drinking water; modified clay materials

\section{Introduction}

A RSENIC REMOVAL FROM drinking water is a very important issue in many regions of Latin America, the United States, India, Bangladesh, China, Japan, and other countries. Nowadays, it is estimated that 226 million people worldwide are exposed to unsafe As concentrations in drinking water (Murcott, 2012). Its occurrence in environmental matrices is associated with natural weathering, volcanic emissions, geochemical reactions, and biological activity. Particularly, in Latin America, most of the environmental problems regarding the presence of As are due to its mobilization under natural conditions (Smedley et al., 2005; Litter et al., 2019). Moreover, mining activities, steel industry, combustion of fossil

*Corresponding author: Institute of Environmental Research and Engineering (IIIA), CONICET, UNSAM, University of San Martín, 25 de Mayo Av. and Francia St., San Martín, Buenos Aires, Argentina. Phone: +54 9112162 0334; E-mail: josemarcobrown@ gmail.com; joseluis.marcobrown@unsam.edu.ar fuels, and use of arsenical pesticides create additional impacts (Apul et al., 2005; Ancelet et al., 2012; Bundschuh et al., 2012; Iriel et al., 2015a). In ground and surface waters, dissolved As is present in inorganic forms either as oxyanions or as neutral species depending on the $\mathrm{pH}$ and oxidative conditions (Smedley and Kinniburgh, 2002; Smedley et al., 2005).

More than 100 years ago, it was stated that long-term exposure to drinking water with As, even in lower concentrations, is responsible for several medical disorders that include dermal disorders (Kazi et al., 2009), cancer, and diabetes (Sinha et al., 2007). Several technologies that were able to remove As from aqueous matrices were proposed in the past decades, with the operational volume and the physicochemical properties of raw water together with economic aspects being the most important factors to decide about their applicability (Litter et al., 2012). Conventional large-scale As removal plants mainly use coagulation-flocculation-filtration with polyaluminum chloride or ferric oxide and reverse osmosis-based methods (Litter et al., 2012). Nevertheless, their implementation in small communities is wasteful to 
provide safe water due to the low population density (Bundschuh et al., 2012).

Emerging and innovative technologies that are suitable to isolated rural and periurban areas such as phytoremediation, the use of zerovalent iron, iron/copper bimetallic nanoparticles, iron-based sorbents, photochemical and geological processes, electrochemical technologies, and the use of low-cost materials as adsorbents have ultimately received more attention (Kumar et al., 2008; Litter et al., 2012; Iriel et al., 2015a, 2015b; Babaee et al., 2018; Alvarez-Cruz and Garrido-Hoyos, 2019; Sherlala et al., 2019; Wang et al., 2019; Xu et al., 2019).

Interestingly, constructed wetlands combine several mechanisms implied in As removal such as adsorption, precipitation of metal sulfide, and plant uptake (Chowdhury et al., 2008). In a critical review, the role of microbial activity, organic matter, and redox potential in the fate and transport of As in constructed wetlands was detailed (Chowdhury, 2017). Prototype wetlands planted with Cyperus haspans and Juncus effusus showed an efficiency close to $90 \%$ to remove As from the rejection of the reverse osmosis process (Corroto et al., 2019).

The efficiency of As removal strongly depends on conditions of the proceedings that can be easily adjusted in a treatment plant. Otherwise, in a level home, minimal handling is required. This constitutes the major problem considering that there is a wide range of possibilities in natural waters regarding $\mathrm{pH}$, conductivity, and major ions. Consequently, removal methods that exhibit good results in a lab may be not good enough at field conditions (Bundschuh et al., 2010). The use of geological materials is an economical and sustainable alternative due to the abundance and low cost (Mohan and Pittman, 2007).

Montmorillonite (Mt) has large specific surface area, layered structure, chemical and mechanical stability, and high cation exchange capacity (CEC). It is found in large deposits around the world and has received attention in both academic and industrial research due to its promising and peculiar features such as adsorbent material, low cost, or for reinforcing polymer nanocomposites, among others (Bhattacharyya and Gupta, 2008; Zhu et al., 2016; Bee et al., 2018). Particularly, pillared and modified clay minerals are interesting materials because of their possibility of being tuneable in terms of their properties (Timofeeva et al., 2009). These materials exhibit multi-charged sites, large surface area, high interlayer space, and thermal stability (Gil et al., 2011).

Pillared materials obtained by solutions containing iron or titanium had demonstrated excellent performance in the adsorption of oxoanions of $\mathrm{As}(\mathrm{III})$ and $\mathrm{As}(\mathrm{V})$ from aqueous solutions (Lenoble et al., 2002; Li et al., 2012). Regarding modified clay minerals, obtaining it is cheaper than the pillared ones since they do not need to be heated during their synthesis.

Several studies were performed on iron-modified clays materials to evaluate their performance for As removal. Grygar et al. (2007) focused on the study of synthesis procedures to obtain information about iron species formed in these materials. These authors also evaluated their performance regarding As adsorption, concluding that the sorption capacity increases with the $\mathrm{Fe} / \mathrm{OH}$ ratio during the synthesis. Luengo et al. (2011) studied the adsorption/desorption kinetics of arsenate on Fe-modified montmorillonite at several $\mathrm{pH}$ values, stirring rates, and As initial concentrations.
Moreover, Ren et al. (2014) reported the adsorption parameters of As adsorbed onto Fe-modified montmorillonite.

Besides these previous papers, there are still questions to be addressed to understand better the applicability of these materials to remove As from natural waters. In a recent work, Bhowmick et al. (2014) presented the kinetic parameters and mechanisms for the As adsorption onto a montomorillonitesupported nanoscale zero-valent iron where the ion's competence and $\mathrm{pH}$ were considered. Although most of the cited articles in this work evaluate the adsorption at several $\mathrm{pH}$, the maxima adsorption capacities are determined at the most favorable $\mathrm{pH}$ condition. Moreover, studies considering conductivity of the media are scarce. In this context, we are interested in evaluating the $\mathrm{As}(\mathrm{V})$ adsorption onto ironmodified clay minerals from a kinetic and equilibrium perspective at natural groundwater conditions and that are the principal mechanisms involved.

\section{Materials and Methods}

\section{Reagents}

All the reagents used were of analytical grade and used without further purification. A stock $\mathrm{As}(\mathrm{V})$ solution of $1,000 \mathrm{mg} / \mathrm{L}$ was prepared by dissolving $4.4570 \mathrm{~g}$ of the salt $\mathrm{Na}_{3} \mathrm{AsO}_{4} \cdot 7 \mathrm{H}_{2} \mathrm{O}$ (Biopack) in a volume of $1 \mathrm{~L}$ by using milliQ water (Millipore $\mathrm{GmbH}$ ). Working solutions were prepared by dilution to obtain $\mathrm{As}(\mathrm{V})$ concentrations ranging from 0.1 to $12 \mathrm{mg} / \mathrm{L}$, which is the range documented for As concentration in groundwater in Latin America (Bundschuh et al., 2012; Litter et al., 2019). The salt $\mathrm{Fe}\left(\mathrm{NO}_{3}\right)_{3} \cdot 9 \mathrm{H}_{2} \mathrm{O}$ (Aldrich) was used for the synthesis of the modified clay material. To adjust $\mathrm{pH}$ of the solutions, $\mathrm{HNO}_{3}$ (Suprapur ${ }^{\circledR}$; Merck) and $\mathrm{KOH}$ solutions (Cicarelli) were utilized. The effects of the counterion and the ionic strength were evaluated with $\mathrm{KNO}_{3}$ (Merck), $\mathrm{NaCl}$ (Cicarelli), and $\mathrm{Na}_{3} \mathrm{PO}_{4} \cdot 12 \mathrm{H}_{2} \mathrm{O}$ (Sigma-Aldrich).

\section{Clay materials}

Montmorillonite API number 26, Clay Spur, Wyoming, was provided by Ward's Natural Science Establishment, Inc. Mt was manually milled in an agate mortar and sieved to a particle size lesser than $125 \mu \mathrm{m}$. The main properties of raw material, reported in a previous work (MarcoBrown et al., 2014), are: CEC $138 \mathrm{meq} 100 \mathrm{~g}^{-1}$ determined by the formaldehyde method (Reeve and Sumner, 1971), purity $>98 \%$ determined by X-ray diffraction (XRD) (Rietveld, 1969), and isoelectric point at $\mathrm{pH}=3.2$ (diffusion potential method) (Tschapek et al., 1989). The structural chemical formula that includes the isomorphic substitutions $\left(\left[\left(\mathrm{Si}_{3.94} \mathrm{~A}_{10.06}\right)\left(\mathrm{Al}_{1.56} \mathrm{Fe}_{0.18} \mathrm{Mg}_{0.26}\right) \mathrm{O}_{10}(\mathrm{OH})_{2}\right] \mathrm{M}^{+}{ }_{0.32}\right)$ was determined from the chemical analysis following the method of Siguín et al. (1994).

Modified clay material (iron modified montmorillonite [Fe-Mt]) was prepared according to Marco-Brown et al. (2012). Briefly, a solution of Fe(III) $1 \mathrm{M}$ was prepared by dissolution of the salt at room temperature with vigorous stirring and the slow addition of a solution of $\mathrm{KOH}(2 \mathrm{M})$, until reaching a molar ratio of $\mathrm{OH}^{-} / \mathrm{Fe}=2$. The solution was kept at room temperature for $4 \mathrm{~h}$ for aging. Mt was added to the Fe(III) solution to obtain an Fe/Mt ratio of $60 \mathrm{mmol} \mathrm{Fe} \mathrm{g}^{-1}$ Mt. The mixture was allowed to react, stirring at room temperature for $12 \mathrm{~h}$. The solid was separated by centrifugation 
and washed with deionized water until a conductivity value lower than $10 \mu \mathrm{S}$ was reached.

\section{Surface characterization of clay materials}

Nitrogen adsorption-desorption isotherms were recorded at $77 \mathrm{~K}$ by using a Micromeritics ASAP 2010 instrument. All samples were degassed at $150^{\circ} \mathrm{C}$ before measurement. The specific surface area was calculated by using the BET method (Brunauer et al., 1938).

Mt and Fe-Mt samples were characterized by Small Angle X-Ray Scattering (SAXS) and Wide Angle X-Ray Scattering (WAXS) to determine changes in the interlayer spacing. Data were obtained at the D01A SAXS line workstation of the Brazilian Synchrotron Light Source (LNLS), Campinas, Brazil, by using a wavelength of $0.155 \mathrm{~nm}$ and a sample to detector distance of $491.334 \mathrm{~mm}$. The recorded scattering vector $(q)$ ranged from 0.25 to $5.9 \mathrm{~nm}$. Measurements were made at room temperature and registered in a $2 \mathrm{D}-\mathrm{CCD}$ detector (MAR-USA $165 \mathrm{~mm}$ ).

The morphology and surface chemical analysis of Mt and Fe-Mt were determined by scanning electron microscopy (SEM) using an FEG-SEM Zeiss Supra 55vp coupled with an energy-dispersive X-ray analyzer (EDX) that provides a qualitative and semiquantitative composition of the sample surface.

The zeta potential was achieved through the measurement of electrophoretic mobility values that were converted by using the Smoluchowski equation. Fe-Mt samples with or without $\mathrm{As}(\mathrm{V})$ adsorbed were dispersed in solutions of 1, 10, and $25 \mathrm{mM} \mathrm{KNO}_{3}$. The $\mathrm{pH}$ was adjusted by adding drops of $\mathrm{KOH}$ or $\mathrm{HNO}_{3}$ from 2 to 11 . Measurements were performed by using a dosage of $200 \mathrm{mg} / \mathrm{L}$ with Zeta Plus light-scattering zeta potential analyzer (Brookhaven Instruments Co.).

\section{Adsorption batch experiments}

Batch experiments were conducted to determine the kinetic and equilibrium parameters of the $\mathrm{As}(\mathrm{V})$ adsorption onto clay material particles. To evaluate the extension of the As adsorption regarding the solution properties, experiments were

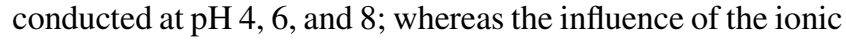
strength was determined by using solutions adjusted at 1,10 , and $25 \mathrm{mM} \mathrm{KNO}_{3}$ (that corresponds to conductivities of 160 , 1,300, and 3,300 $\mu \mathrm{S}$, Hanna, HI 255). Experiments were also performed in the presence of $\mathrm{NaCl}$ and $\mathrm{Na}_{3} \mathrm{PO}_{4}$ electrolytes. For that, $0.25 \mathrm{mg}$ of adsorbent (Mt or Fe-Mt) was dispersed in $1 \times 10^{-2} \mathrm{mM} \mathrm{As}(\mathrm{V})$ solutions with a molar ratio of 1:100 arsenic:electrolyte.

Kinetic studies were performed to evaluate the effect of the contact time on the As(V) adsorption. Thus, $300 \mathrm{~mL}$ of $\mathrm{As}(\mathrm{V})$ solution of $1 \mathrm{mg} / \mathrm{L}$ with $0.15 \mathrm{~g}$ of adsorbent $(\mathrm{Fe}-\mathrm{Mt})$ at constant $\mathrm{pH}=8$ and ionic strength of $1 \mathrm{mM} \mathrm{KNO}_{3}$ was mechanically stirred $(300 \mathrm{rpm})$ for $24 \mathrm{~h}$. During this time, several aliquots were taken and the supernatant was separated by centrifugation and filtration (cellulose nitrate membrane, $0.45 \mu \mathrm{m}$ ). Samples were acidified to $0.5 \%$ with $\mathrm{HNO}_{3}$ and stored at $4^{\circ} \mathrm{C}$ until the As measurement.

Equilibrium experiments were performed with $\mathrm{As}(\mathrm{V})$ working solutions with concentrations ranging from 0.1 to $12 \mathrm{mg} / \mathrm{L}$ and a dose of $0.5 \mathrm{~g} / \mathrm{L}$ of adsorbent (Fe-Mt), at constant $\mathrm{pH}=8$. Dispersions were maintained on agitation at room temperature for $6 \mathrm{~h}$ and then As concentration was evaluated in the supernatant.

\section{Arsenic measurements}

As $(V)$ concentration in sampled solutions was measured by Inductively coupled plasma-optical emission spectrometry (ICP-OES, Optima DV 2000; Perkin Elmer) according to the methodology reported by Iriel et al. (2015a). From these measurements, the clay mineral adsorption coverage $\Gamma_{e}$ for $\mathrm{As}(\mathrm{V})$ was calculated as:

$$
\Gamma_{\mathrm{e}}=\frac{\left(\mathrm{C}_{0}-\mathrm{C}_{\mathrm{e}}\right) \mathrm{V}}{\mathrm{m}}
$$

where both $\mathrm{C}_{0}$ and $\mathrm{Ce}$ are $\mathrm{As}(\mathrm{V})$ concentration at initial and equilibrium time in the solution $(\mathrm{mg} / \mathrm{L})$, respectively; $\mathrm{m}$ is the clay mineral mass $(\mathrm{g})$; and $\mathrm{V}$ is the volume of the solution (L). In adsorption kinetic experiments, $\Gamma_{t}$ is calculated in a similar way to $\Gamma_{e}$ but $\mathrm{C}_{\mathrm{e}}$ is replaced by $\mathrm{C}_{\mathrm{t}}$ $(\mathrm{As}(\mathrm{V})$ concentration at a given time $t)$. As(V) removal $(\%)$ was estimated as:

$$
\% \text { Removal }=\frac{\left(\mathrm{C}_{0}-\mathrm{C}_{\mathrm{e}}\right) \times 100}{\mathrm{C}_{0}}
$$

\section{Kinetic and equilibrium adsorption models}

Kinetic analysis. Kinetic parameters from adsorption process have been obtained by fitting experimental data to pseudo-first order (PFO), pseudo-second order (PSO), and intra-particle diffusion model (IDM) equations (Areco et al., 2013; Haerifar and Azizian, 2013; Marco-Brown et al., 2014) and to the mixed surface reaction and diffusion-controlled adsorption kinetic model (MSR/DCK), recently proposed (Haerifar and Azizian, 2013). For further information about kinetic models used in this work, see Supplementary Data.

Equilibrium studies. Adsorption isotherms are extremely helpful for optimizing the use of adsorbent materials, because they describe the nature of the interaction between the sorbate and the adsorbent. The analysis of the experimental data is useful for the practical design and operation of adsorption systems. There are several expressions used for description of adsorption isotherms, with Langmuir and Freundlich models being the most widely applied for the interpretation of adsorption processes in a wide variety of adsorbents. For further information regarding isotherm models used in this work, see Supplementary Data.

\section{Statistical analysis}

Analysis was performed by Sigmaplot 11.0 software to determine adsorption isotherm and kinetic parameters of the cited models. Infostat ${ }^{\circledR}$ statistical software (Di Rienzo et al., 2011) was used to perform the analysis of variance and the Pearson correlations. Previously, a normal distribution for the whole data set was confirmed by using the Shapiro-Wilks modified test and variance homogeneity was proved with the Levene test.

\section{Results and Discussion}

\section{Characterization of clay materials}

All materials presented a type II nitrogen adsorption-desorption isotherm (Fig. 1A) with a type H3 hysteresis 
FIG. 1. (A) $\mathrm{N}_{2}$ adsorption/ desorption isotherms on $\mathrm{Mt}$ and $\mathrm{Fe}$ Mt. (B) SAXS/WAXS patterns for Mt and Fe-Mt. (C, D) SEM images of $\mathrm{Mt}$ and $\mathrm{Fe}-\mathrm{Mt}$, respectively. Insets in $(\mathbf{C}, \mathbf{D})$ oxide $(\%)$ determined by EDX in Mt and Fe-Mt, respectively. EDX, energy-

dispersive X-ray analyzer; Fe-Mt, iron-modified montmorillonite; Mt, montmorillonite; SAXS, small angle X-ray scattering; SEM, scanning electron microscopy; WAXS, wide angle $\mathrm{X}$-ray scattering.
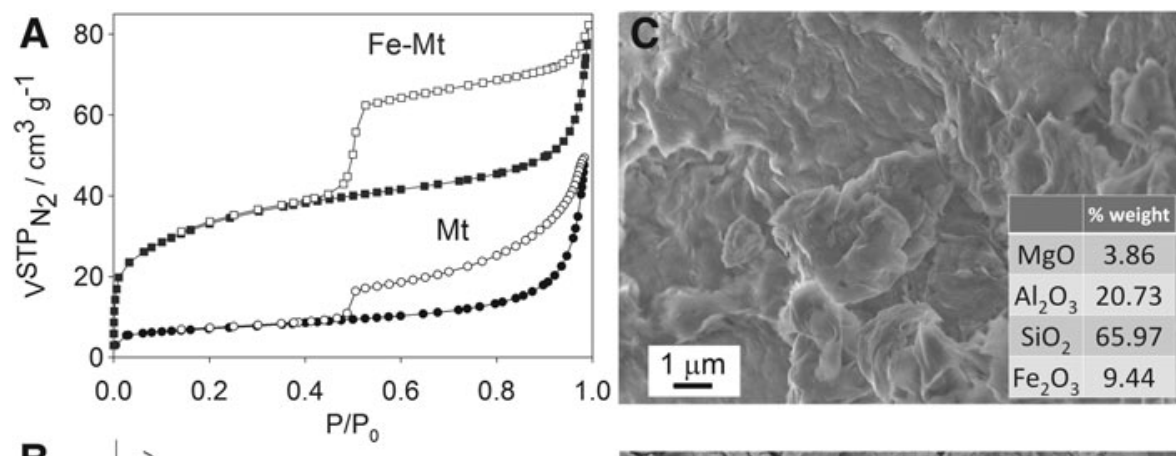

B

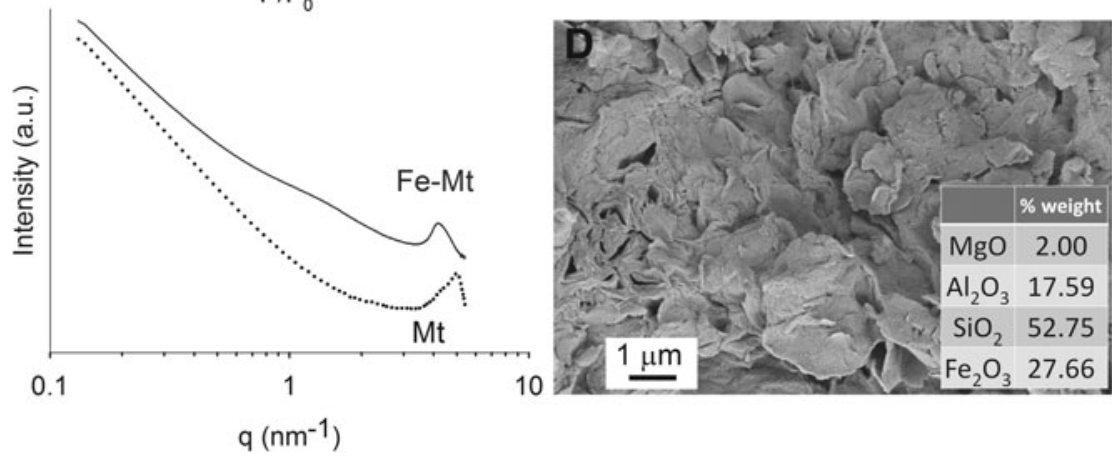

associated with low porosity materials formed by sheet agglomerations. The specific surface areas were 24 and $107 \mathrm{~m}^{2} / \mathrm{g}$ and the pore volumes were 0.04 and $0.09 \mathrm{~cm}^{3} / \mathrm{g}$ for $\mathrm{Mt}$ and Fe-Mt, respectively. WAXS and SAXS patterns for Mt and Fe-Mt samples are shown in Fig. 1B, where an increment from 1.26 to $1.49 \mathrm{~nm}$ in the basal space was detected, suggesting the intercalation of Fe oligomers into the interlayer space. The SEM image of Mt (Fig. 1C) showed face-toedge contact between the particles with random orientation, and no formation of domains (group of particles that act as a unit) or clusters (group of domains that act as a unit), whereas agglomerates were identified. The SEM image of Fe-Mt is shown in Fig. 1D, where pore spaces can be identified; particles with sizes between 100 and $500 \mathrm{~nm}$ corresponding to coaggregate or iron oxide particles on the surface and randomly dispersed are observed. Insets in Fig. 1C and D show the clay mineral composition expressed as oxides (\%), where the Fe incorporation on Fe-Mt was evidenced by the increase of $\mathrm{Fe}_{2} \mathrm{O}_{3}(\%)$ from 9.44 to 27.66 .

\section{Influence of $\mathrm{pH}$ and of coexisting ions}

The dependence of the solution $\mathrm{pH}$ on the solute adsorption is mainly related to the surface functional groups of the sorbent and the charge of the species into the solution. Figure 2A showed the adsorption capacities for Mt and Fe-Mt in contact with an $\mathrm{As}(\mathrm{V})$ solution of $3 \mathrm{mg} / \mathrm{L}$ equilibrated at $\mathrm{pH} \mathrm{4,} \mathrm{6,} \mathrm{and} \mathrm{8.} \mathrm{Results} \mathrm{indicated} \mathrm{that} \mathrm{Fe-Mt} \mathrm{had} \mathrm{a} \mathrm{maxima}$ value of $5.3 \mathrm{~g} \mathrm{As} \mathrm{kg}^{-1}$ at $\mathrm{pH}$, which corresponds to $90 \%$ of the initial concentration. However, a significant diminution at pH 6 was observed where the adsorption (\%) was nearly 80\%; whereas at $\mathrm{pH} 8$, a minimal adsorption of $2.9 \mathrm{~g} \mathrm{As} \mathrm{kg}^{-1}$ that corresponds to the $50 \%$ was observed. From $\mathrm{H}_{3} \mathrm{AsO}_{4}$ acidity, constant values $\left(\mathrm{pKa}_{1}: 2.28 ; \mathrm{pKa}_{2}: 6.97\right.$ and $\left.\mathrm{pKa}_{3}: 11.6\right)$ (Wang et al., 2017) can be estimated, proving that the predominant species are $\mathrm{H}_{2} \mathrm{AsO}_{4}{ }^{-}$at $\mathrm{pH}=4, \mathrm{H}_{2} \mathrm{AsO}_{4}{ }^{-}$and $\mathrm{HAsO}_{4}{ }^{2-}$ at $\mathrm{pH}=6$, and $\mathrm{HAsO}_{4}{ }^{2-}$ at $\mathrm{pH}=8$. Taking into account this feature where the $\mathrm{As}(\mathrm{V})$ removal $(\%)$ diminishes as the $\mathrm{pH}$ increases, it can stated that Fe-Mt exhibited an anionic adsorption profile.

Similar results have been reported for the adsorption of picloram (anionic herbicide) on raw clays and Fe oxides modified motmorillonite (Marco-Brown et al., 2012, 2014,
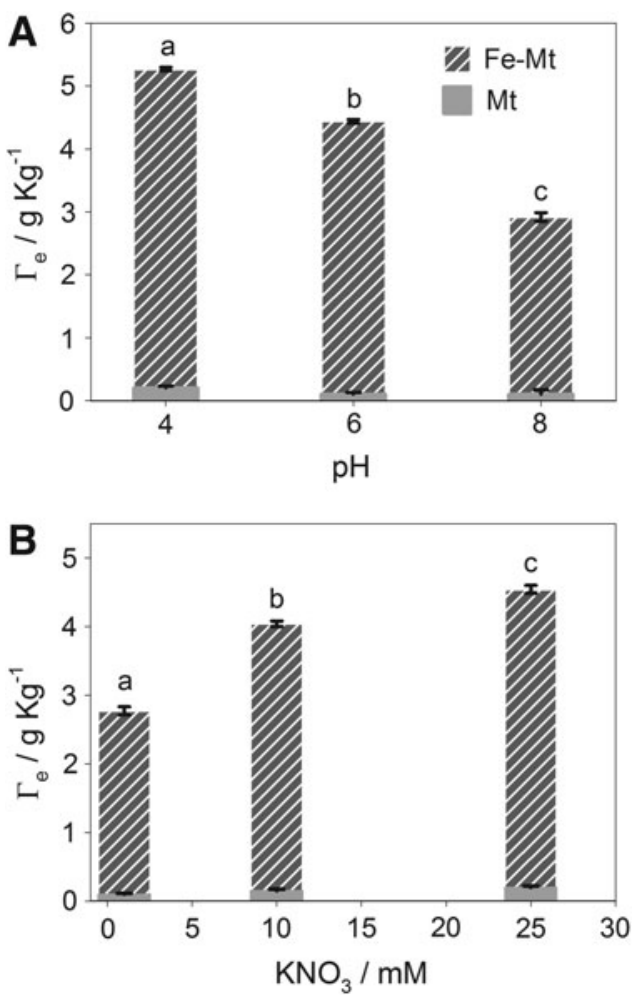

FIG. 2. Adsorption of $\mathrm{As}(\mathrm{V})$ from a $3 \mathrm{mg} / \mathrm{L}$ starting solution by $\mathrm{Mt}$ and Fe-Mt (clay mineral dosage of $5 \mathrm{mg} / \mathrm{L}$ ) (A) as a function of $\mathrm{pH}$ under ionic strength of $\mathrm{KNO}_{3} 1 \mathrm{mM}$; and (B) as a function of ionic strength at $\mathrm{pH} 8$. Error bars are standard errors, and different letters represent significant differences at $p<0.05$. 
2015, 2019) and nitrate adsorption on biochars (Chintala et al., 2013). Antelo et al. (2005) reported the adsorption of arsenate on goethite varies with the ionic strength $\left(0.1-0.01 \mathrm{M} \mathrm{KNO}_{3}\right)$ and $\mathrm{pH}$ (4-10). They also observed that the As adsorption decreases as the $\mathrm{pH}$ increases. Analogous results have been reported for the adsorption of $\mathrm{As}(\mathrm{III})$ and $\mathrm{As}(\mathrm{V})$ onto variable charge soils (Xu et al., 2010). Regarding our results, it was observed that even when Fe-Mt had a better performance in acidic media, in both neutral and basic conditions, Fe-Mt possess an excellent efficiency for $\mathrm{As}(\mathrm{V})$ removal. For instance, nearly $80 \%$ and $50 \%$ of arsenate was removed at $\mathrm{pH} 6$ and 8 , respectively. This is a very important result that indicates that modified Fe-Mt is able to be used in natural waters without the previous acidification procedure, and, consequently, it could be implemented at a household level.

The effect of ionic strength on the $\mathrm{As}(\mathrm{V})$ adsorption process was evaluated to determine the capability of these materials to remove $\mathrm{As}(\mathrm{V})$ anions in natural waters with different salt content. Moreover, the presence of electrolytes in the media allows discerning between the specific and nonspecific nature of the binding evaluating the changes in As(V) adsorption (Partey et al., 2009). In particular, changing the background electrolyte concentration influences adsorption in at least two ways: (1) by affecting the interfacial potentials and (2) by the competition between the electrolyte anions and the anionic adsorbing species for the available sites for adsorption (Hayes et al., 1988).

Figure 2B shows a significant enhancement of $\mathrm{As}(\mathrm{V})$ adsorption as the $\mathrm{KNO}_{3}$ concentration increases, as has been indicated for anion adsorption on hydrous oxide materials (Hayes et al., 1988; Liu et al., 2008). A marked reduction of anion adsorption with increasing ionic strength suggests an outer-sphere complex formation. Otherwise, when anion adsorption is relatively unaffected by changes in ionic strength, the adsorption process could be associated with an inner-sphere complex formation. Results presented in Fig. 2B are not only indicative of an inner-sphere adsorption mechanism for arsenate onto $\mathrm{Fe}-\mathrm{Mt}$ but also indicate that the use of $\mathrm{Fe}-\mathrm{Mt}$ as $\mathrm{As}(\mathrm{V})$ adsorbent is appropriate in natural waters with high conductivity. The competition of $\mathrm{As}(\mathrm{V})$ adsorption (at $\mathrm{pH} 8$ ) with other ions such as chloride $\left(\mathrm{Cl}^{-}\right)$and phosphate $\left(\mathrm{PO}_{4}{ }^{3-}\right)$ was determined in Fe-Mt samples in this study, and the results indicated that $\mathrm{As}(\mathrm{V})$ removal by $\mathrm{Fe}-\mathrm{Mt}$ increased in the following order: $\mathrm{PO}_{4}{ }^{3-}(0.96 \%)<\mathrm{Cl}^{-}(30.64 \%)<$ $\mathrm{NO}_{3}{ }^{-}(47.15 \%)$, showing a greater decrease in arsenic adsorption in the presence of phosphate. Adsorption from strong anions such as $\mathrm{Cl}^{-}, \mathrm{NO}_{3}^{-}, \mathrm{Br}^{-}$, and $\mathrm{ClO}_{4}{ }^{-}$to functional groups on the surface of mineral acids occurs through outersphere complexation processes that are driven mainly by electrostatic forces (Essington, 2004; Marco-Brown et al., 2017b). The adsorption of phosphate on metal oxides has been reported to occur by inner-sphere complexation processes, interacting with a metal center via formation of monodentate or bidentate complexes or with two adjacent metal centers by forming a bridge complex (Higuchi and Connors, 1965; He et al., 1997; Marco-Brown et al., 2017b). Therefore, these results could indicate that $\mathrm{As}(\mathrm{V})$ adsorption onto the surface of Fe-Mt occurs by forming an inner-sphere complex. To confirm the inner-sphere complex formation, the zeta potential of Fe-Mt particle dispersions with and without adsorbed $\mathrm{As}(\mathrm{V})$ was determined at different $\mathrm{pH}$ values. Results are shown in Fig. 3.
Zeta potential for Fe-Mt dispersions in $\mathrm{KNO}_{3}$ solutions showed negative values in the entire range of studied $\mathrm{pH}$ (Fig. 3A). The distribution observed for Fe-Mt was a combination between the zeta potential observed for Mt (MarcoBrown et al., 2012) and for iron(III) (hydr)oxides (Tombácz et al., 2001). The iron incorporation in the clay mineral
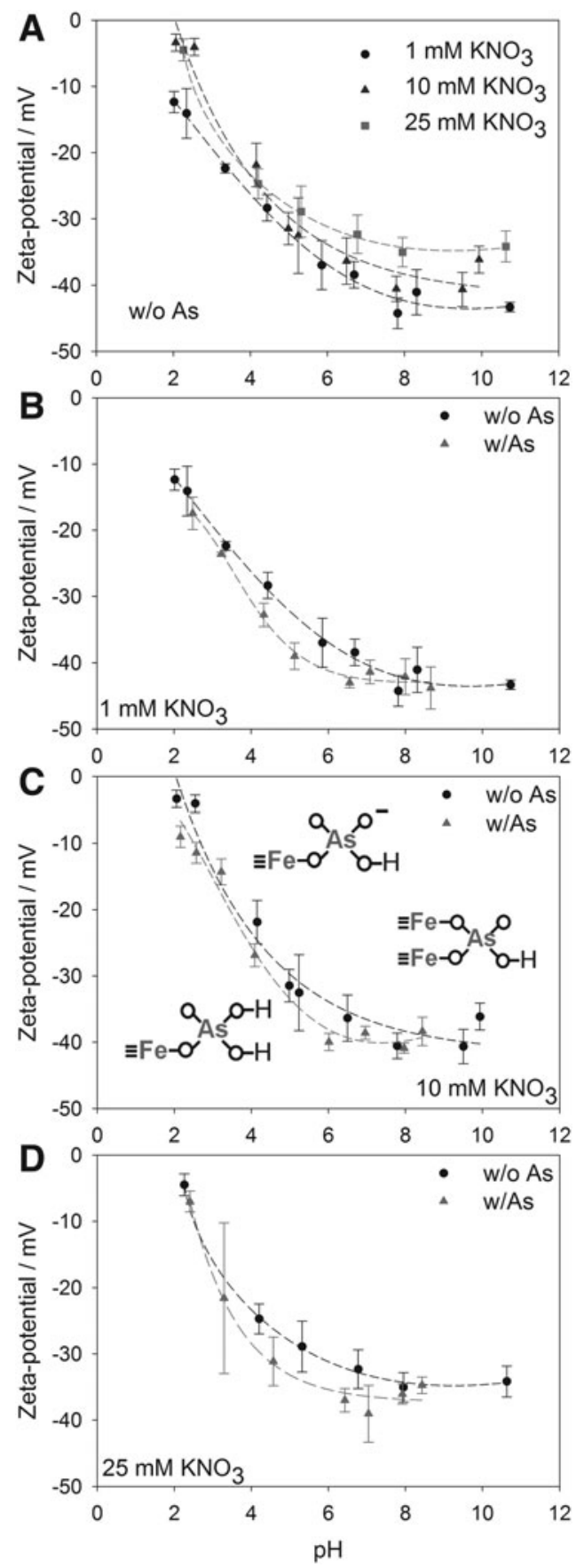

FIG. 3. Zeta potential of Fe-Mt particles as a function of pH. (A) Fe-Mt dispersed in 1,10 , and $25 \mathrm{mM}$ of $\mathrm{KNO}_{3}$; (B-D) Fe-Mt with (w/As) and without (w/o As) $\mathrm{As}(\mathrm{V}) \mathrm{ad}-$ sorbed and dispersed in 1,10 , and $25 \mathrm{mM}$ of $\mathrm{KNO}_{3}$, respectively. The dashed lines are placed on graphs as a guide to the eye. Insets in $(\mathbf{C})$ are the main $\mathrm{As}(\mathrm{V})$ surface complex species in a different $\mathrm{pH}$ domain. 
structure changed the surface properties by adding iron metallic centers. In addition, $\mathrm{Fe}$ (III) has a different acid-base behavior than the groups normally present on the Mt surface (sylanol and aluminol). The variation of zeta potential values with ionic strength observed in Fig. 3A is typical of hydrous ferric oxide materials (Stumm, 1992). From Fig. 3A, a point zero charge (PZC) of Fe-Mt could be estimated around $\mathrm{pH} 2$.

The iron atoms located at the Fe-Mt surface are coordinated to oxygen atoms, where they can be in several forms such as protonated $\left(\equiv \mathrm{FeOH}_{2}^{+}\right)$, neutral $(\equiv \mathrm{FeOH})$, or deprotonated $\left(\equiv \mathrm{FeO}^{-}\right)$depending on the solution $\mathrm{pH}$. At $\mathrm{pH}$ values lower than 4, the reaction may occur at Fe-Mt surface as is indicated in Equation (3), where the interaction of the main $\mathrm{As}(\mathrm{V})$ species at $\mathrm{pH} 4\left(\mathrm{H}_{2} \mathrm{AsO}_{4}{ }^{-}\right)$with surface sites occurs by forming a monodentate inner-sphere complex $\left(\equiv \mathrm{FeOAsO} \mathrm{H}_{2}\right.$ ) and the leaving group is the hydroxyl anion. Similar reactions can be described for $\equiv \mathrm{FeOH}_{2}^{+}$and $\equiv \mathrm{FeO}^{-}$ surface sites and with water and/or hydroxyl anion being the leaving groups. The monodentate complex is formed without changes in the surface charge or with an increase in the negative charge depending on the surface charge balance. Then, the surface charges of Fe-Mt with As(V) and without As $(\mathrm{V})$ adsorbed had a similar result, as is observed in Fig. 3B-D. This effect was observed at the three $\mathrm{KNO}_{3}$ concentrations: 1,10 , and $25 \mathrm{mM}$.

$$
\equiv \mathrm{FeOH}+\mathrm{H}_{2} \mathrm{AsO}_{4}^{-} \quad \Leftrightarrow \quad \equiv \mathrm{FeOAsO}_{3} \mathrm{H}_{2}+\mathrm{OH}^{-}
$$

At a $\mathrm{pH}$ around 6, the reactions that may occur at the Fe-Mt surface are indicated in Equations (3) and (4). The interaction of main $\mathrm{As}(\mathrm{V})$ species at $\mathrm{pH} 6\left(\mathrm{H}_{2} \mathrm{AsO}_{4}{ }^{-}\right.$and $\left.\mathrm{HAsO}_{4}{ }^{2-}\right)$ with surface sites occurs by forming a new monodentate innersphere complex ( $\equiv \mathrm{FeOAsO}_{3} \mathrm{H}^{-}$), and the leaving groups are hydroxyls in both cases. Nevertheless, the surface charge of Fe-Mt with $\mathrm{As}(\mathrm{V})$ adsorbed is much more negative than $\mathrm{Fe}-$ Mt without As(V) adsorbed (Fig. 3B-D). The main reaction on the Fe-Mt surface is represented in Equation (4).

$$
\equiv \mathrm{FeOH}+\mathrm{HAsO}_{4}^{2-} \Leftrightarrow \quad \equiv \mathrm{FeOAsO}_{3} \mathrm{H}^{-}+\mathrm{OH}^{-}
$$

The monodentate surface complex $\equiv \mathrm{FeOAsO}_{3} \mathrm{H}_{2}$ may suffer acid-base dissociation and be converted to the second monodentate surface complex, $\equiv \mathrm{FeOAsO}_{3} \mathrm{H}^{-}$, by loss of an acidic proton, increasing the negative charge on the surface, as is indicated in Equation (5). Similar results had been informed for the adsorption of inorganic and organic anionic molecules on hydrous ferric oxides, raw and modified Mt materials (dos Santos Afonso and Stumm, 1992; Khoury et al., 2010; Marco-Brown et al., 2015; Flores et al., 2018).

$$
\equiv \mathrm{FeOAsO}_{3} \mathrm{H}_{2} \quad \Leftrightarrow \quad \equiv \mathrm{FeOAsO}_{3} \mathrm{H}^{-}+\mathrm{H}^{+}
$$

As the $\mathrm{pH}$ increases, the charge difference between Fe-Mt with and without $\mathrm{As}(\mathrm{V})$ adsorbed samples is becoming smaller and the slope of the zeta potential versus $\mathrm{pH}$ for $\mathrm{Fe}-$ Mt with the $\mathrm{As}(\mathrm{V})$ adsorbed sample becomes flat. At a $\mathrm{pH}$ around 8, the reactions that may occur at the Fe-Mt surface are indicated in Equations (4) and (6). The interaction of the main $\mathrm{As}(\mathrm{V})$ species at $\mathrm{pH} 8\left(\mathrm{HAsO}_{4}{ }^{2-}\right)$ with surface sites may occur by forming a monodentate [Eq. (4)] and/or bidentate [Eq. (6)] inner-sphere complexes, and the leaving groups are hydroxyls in both cases. Nevertheless, the surface charge of
Fe-Mt with $\mathrm{As}(\mathrm{V})$ adsorbed is similar compared with Fe-Mt without As(V) adsorbed (Fig. 3B-D), demonstrating that the main reaction occurred at the Fe-Mt surface at $\mathrm{pH} 8$, as indicated in Equation (6).

$$
2 \equiv \mathrm{FeOH}+\mathrm{HAsO}_{4}^{2-} \quad \Leftrightarrow \quad(\equiv \mathrm{FeO})_{2} \mathrm{AsO}_{2} \mathrm{H}+2 \mathrm{OH}^{-}
$$

In Fig. 3C (insets), the main As(V) surface complexes species at different $\mathrm{pH}$ domains were schematized. These results provide indirect and conclusive evidence about the formation of surface complexes between the surface of the Fe-Mt particles and As(V), confirming an inner-sphere complex formation.

\section{Adsorption kinetics}

Due to the low quantity of $\mathrm{As}(\mathrm{V})$ adsorbed onto Mt (lower than 5\%), kinetics and adsorption parameters were determined by using only Fe-Mt as adsorbent. Kinetic experiments were performed while evaluating the $\mathrm{As}(\mathrm{V})$ concentration from the solution as a function of time. Surface coverage of $\mathrm{As}(\mathrm{V})$ on Fe-Mt was calculated by using Equation (1) and plotted according to PFO, PSO, IDM, and MSR/DCK models (Supplementary Data), as is shown in Fig. 4. The first fitting indicated that the Lagergren model did not fit the experimental data due to $R^{2}$ being lower than 0.01 (Fig. 4A). Regarding the PSO model, an excellent agreement was observed over the entire range of time (Fig. 4B). In addition, the plot of $\mathrm{q}_{\mathrm{t}}$ versus $t^{1 / 2}$ for $\mathrm{As}(\mathrm{V})$ adsorption on Fe-Mt is shown in Fig. 4C. The diffusion kinetic plots exhibited the three-stage linearity, which indicates that two or more steps occur in the adsorption processes (Peng et al., 2016; Marco-Brown et al., 2017a, 2018). The first portion (corresponding to initial times) had been related to high adsorption rate on the external surface of the adsorbent, which has enough available adsorption sites. Afterward, the adsorption rate diminishes due to the difficulty in $\mathrm{As}(\mathrm{V})$ reaching the adsorption sites in the inner pores of Fe-Mt, where the intra-particle diffusion is the rate-controlling step. The $k_{\text {id }}$ and $C$ constant values were obtained from the slope and intercept from the linear regression of the second portion (intermediate times) of the curve, respectively (Doğan et al., 2009). In addition, the curve did not pass through the origin, which indicates that diffusion through the pores is not the limiting factor (Guo et al., 2014). The $C$ value [Eq. (S3), Supplementary Data] reflects the boundary layer effect. The larger the intercept of the plot, the greater the contribution of the surface sorption in the rate-limiting step. Finally, the third portion is the final equilibrium stage, where the intra-particle diffusion starts to slow down due to the low $\mathrm{As}(\mathrm{V})$ concentration in solution (Sun and Yang, 2003). Hence, the three-stage linearity of intra-particle diffusion plots confirmed the presence of both surface adsorption and intra-particle diffusion (Guo et al., 2014) as was proposed by PSO modeling. Thus, the adsorption process has a complicated nature involving both surface adsorption and intra-particle diffusion (Doğan et al., 2009). In conclusion, the adsorption of $\mathrm{As}(\mathrm{V})$ on Fe-Mt involved a two-step mechanism, a rapid one occurring on the external surface followed by a slower process that occurs on the pores by interlayer diffusion as was previously reported (Luengo et al., 2011). 

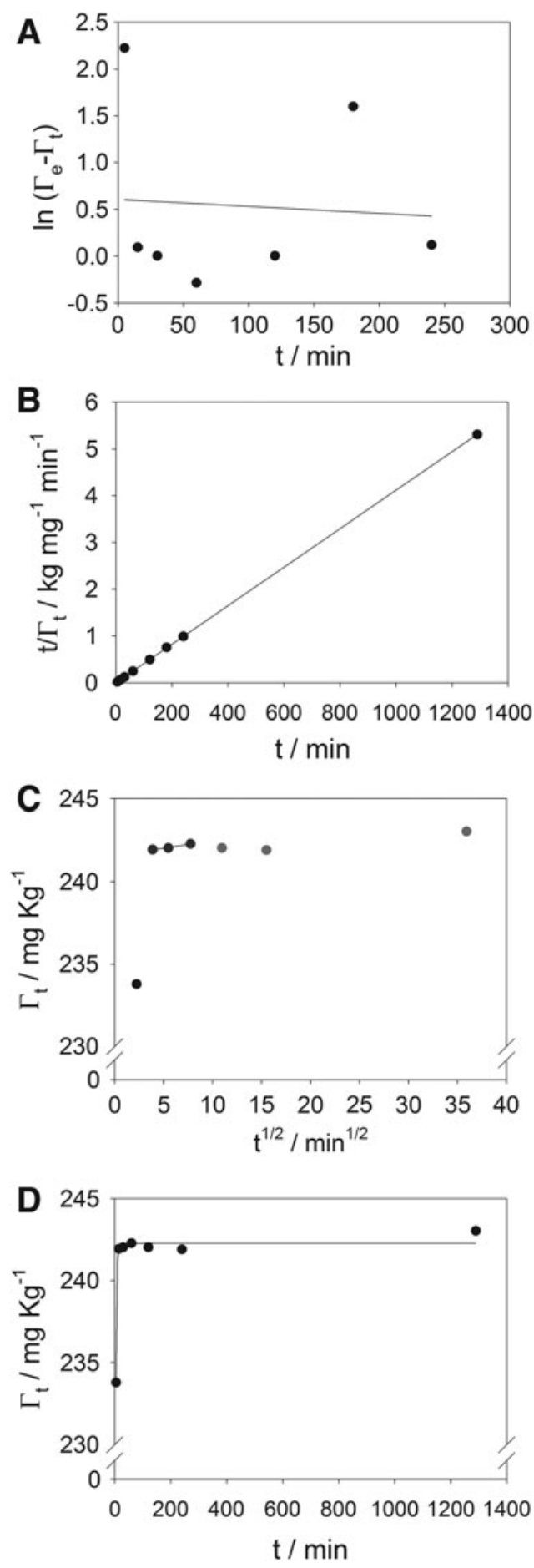

FIG. 4. Fitting of experimental data of $\mathrm{As}(\mathrm{V})$ adsorption onto $\mathrm{Fe}-\mathrm{Mt}$ at $\mathrm{As}(\mathrm{V})$ initial concentration $3 \mathrm{mg} / \mathrm{L}$, solid dosage $0.5 \mathrm{~g} / \mathrm{L}, \mathrm{pH} 8$, and ionic strength $1 \mathrm{mM} \mathrm{KNO}_{3}$. (A) Pseudo-first order, (B) pseudo-second order, (C) intraparticle diffusion, and (D) mixed surface reaction and diffusion-controlled kinetic models.

Haerifar and Azizian (2013) have proposed a new model that can be used when diffusion and surface reaction control the overall rate of the process at the solid/solution interface. In these cases, the mixed surface reaction and diffusioncontrolled kinetic model can be applied, where the surface
Table 1. Parameters Obtained for Kinetic Models FOR As(V) Adsorption onto Fe-Mt

\begin{tabular}{llc}
\hline Model & \multicolumn{1}{c}{ Parameter } & Value \\
\hline PFO & $k_{1} \times 10^{4}\left(\mathrm{~min}^{-1}\right)$ & 7.47 \\
& $R^{2}$ & $<0.005$ \\
PSO & $k_{2} \times 10^{3}(\mathrm{~kg} /[\mathrm{mg} \cdot \mathrm{min}])$ & 5.01 \\
& $\Gamma_{e}(\mathrm{mg} / \mathrm{kg})$ & 243.11 \\
& $R^{2}$ & 0.9999 \\
$\mathrm{IDM}$ & $k_{\mathrm{id}}\left(\mathrm{mg} \cdot \mathrm{kg}^{-1} \cdot \mathrm{min}^{-1 / 2}\right)$ & 0.091 \\
& $C_{(\mathrm{mg} / \mathrm{kg})}$ & 241.57 \\
& $R^{2}$ & 0.9756 \\
MSR/DCK & $\Gamma_{e}(\mathrm{mg} / \mathrm{kg})$ & 242.28 \\
& $\mu_{\mathrm{e}}$ & 0.999 \\
& $k(\mathrm{~L} /[\mathrm{mg} \cdot \mathrm{min}])$ & 67.31 \\
& $\tau(\mathrm{min})$ & 1.05 \\
& $R^{2}$ & 0.9870
\end{tabular}

Fe-Mt, iron-modified montmorillonite; IDM, intra-particle diffusion model; MSR/DCK, mixed surface reaction and diffusion-controlled kinetic model; PFO, pseudo-first order; PSO, pseudo-second order.

coverage as a function of time is modeled according to Equation (S4) (Supplementary Data) (Fig. 4D). The obtained value of $\tau$ is $>0$, which means the presence of diffusion in conjunction with surface reaction. A $\mu_{\text {eq }}$ value near to 1 indicated that $\mathrm{As}(\mathrm{V})$ was completely removed from the solution by Fe-Mt. Further, the good correlation of the MSR/DCK model with the experimental data is indicated by the high value of $R^{2}$ and the $\Gamma_{e}$ value of $242.28 \mathrm{mg} / \mathrm{kg}$. Also, the $\tau$ value confirms the previous results obtained by IDM adjustment, indicating that $\mathrm{As}(\mathrm{V})$ adsorption on Fe-Mt occurs through both surface adsorption and intra-particle diffusion processes. Kinetic parameters derived from the evaluated models are presented in Table 1.

\section{Adsorption isotherm models}

Equilibrium studies were performed to determine the adsorption mechanism of $\mathrm{As}(\mathrm{V})$ on Fe-Mt and the adsorption maxima capacity of the synthesized material. For that, batch Fe-Mt dispersions with $\mathrm{As}(\mathrm{V})$ concentrations ranging from

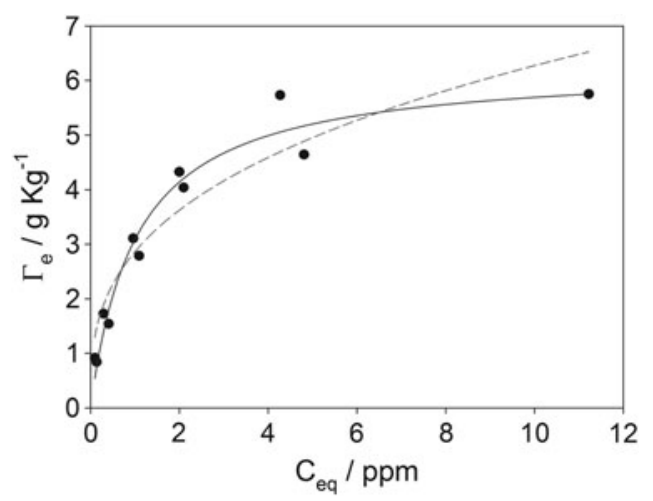

FIG. 5. As(V) adsorption isotherms on iron-modified clay material at Fe-Mt dosage $0.5 \mathrm{~g} / \mathrm{L}, \mathrm{pH} 8$, and ionic strength $1 \mathrm{mM} \mathrm{KNO}_{3}$. Solid and dashed lines were obtained by using Langmuir and Freundlich models, respectively. 
Table 2. Langmuir and Freundlich Parameters for As(V) Adsorption on Fe-Mt at Solid Dosage $0.5 \mathrm{~g} / \mathrm{L}$, $\mathrm{PH}$, and IONIC STREngth $1 \mathrm{MM} \mathrm{KNO}_{3}$

\begin{tabular}{lll}
\hline Model & Parameter & Value \\
\hline Langmuir & $\Gamma_{\max }(\mathrm{g} / \mathrm{kg})$ & 6.28 \\
& $\mathrm{~K}_{\mathrm{L}}(\mathrm{L} / \mathrm{mg})$ & 0.966 \\
$R^{2}$ & 0.9597 \\
Freundlich & $\mathrm{K}_{\mathrm{F}}$ & 2.86 \\
& $1 / n$ & 0.341 \\
& $R^{2}$ & 0.8988 \\
\hline
\end{tabular}

0.1 to $12 \mathrm{mg} / \mathrm{L}$ were equilibrated at $\mathrm{pH} 8$ and the ionic strength was set at $1 \mathrm{mM} \mathrm{KNO}_{3}$. The ratio between the quantity of $\mathrm{As}(\mathrm{V})$ adsorbed onto the Fe-Mt particles and the remaining into the solution was fitted to the Freundlich and Langmuir models (Supplementary Data).

From Fig. 5, it is observed that either the Langmuir or Freundlich equations [Eqs. (S5) and (S6), Supplementary Data] are applicable to adsorption experimental data. In the first model, the affinity between sorbent and sorbate is represented by the constant $\mathrm{K}_{\mathrm{L}}$. In general, for good sorbents high $\Gamma_{\max }$ and high $\mathrm{K}_{\mathrm{L}}$ are desirable. The $\mathrm{K}_{\mathrm{L}}$ for $\mathrm{As}(\mathrm{V})$ sorption on Fe-Mt expressed as L/mg was 0.966 (Table 2). The same behavior was observed for the adsorption of As(V) onto zero-valent ions on $\mathrm{Mt}$, where a $\mathrm{K}_{\mathrm{L}}$ value of $0.005 \mathrm{~L} / \mathrm{mg}$ was reported (Bhowmick et al., 2014). Moreover, the $\Gamma_{\max }$ for As $(\mathrm{V})$ obtained from the Langmuir model $(6.28 \mathrm{~g} / \mathrm{kg})$ is near to the experimental one. In addition, both are within the range reported earlier for $\mathrm{As}(\mathrm{V})$ adsorption on iron clay material: $4 \mathrm{~g} / \mathrm{kg}$ (Lenoble et al., 2002) and $7.6 \mathrm{~g} / \mathrm{kg}$ (Luengo et al., 2011) at more acidic $\mathrm{pH}$ values.

The Fe-Mt performance to remove $\mathrm{As}(\mathrm{V})$ was compared with that of other clay minerals in Table 3.

From Table 3, it should be noticed that the synthetic routes of mineral materials affect the performance with regard to As removal. This is a very important issue to be considered due to the cost of the modified material being associated with the synthesis procedures. In addition, it is observed that the final Fe content needs to be optimized. Regarding their implementation at a domiciliary level, it is necessary to provide data according to the natural conditions of $\mathrm{pH}$ and conductivity to assure their applicability to achieve safe As concentration for drinking water.

The study of low-cost adsorbents for As(V) removal has a promising future in the development of technologies aimed at mitigating the problem of As in drinking water in periurban

Table 3. Comparison of Adsorption Capacities Reported in the Literature for As(V) on Modified Clays

\begin{tabular}{|c|c|c|c|c|}
\hline Sorbent & $\begin{array}{l}\text { Experimental } \\
\text { conditions }\end{array}$ & $\Gamma_{\max }, g / \mathrm{kg}$ & $\begin{array}{c}\text { Applied adsorption } \\
\text { isotherms and kinetic models }\end{array}$ & References \\
\hline $\begin{array}{l}\text { Nanoscale zero-valent } \\
\text { iron on } \\
\text { montmorillonite }\end{array}$ & $\begin{array}{l}\mathrm{pH} 7 \text {, contact time: } \\
4 \mathrm{~h} \text {, sorbent dosage: } \\
1.26 \mathrm{~g} / \mathrm{L} .\end{array}$ & 45.5 & $\begin{array}{l}\text { Langmuir and Freundlich isotherms, } \\
\text { PSO kinetics. Adsorption } \\
\text { diminishes at basic pH values. } \\
\mathrm{PO}_{4}{ }^{3-} \text { competence decreased the } \\
\mathrm{As}(\mathrm{V}) \text { adsorption. }\end{array}$ & $\begin{array}{l}\text { Bhowmick } \\
\text { et al. } \\
\text { (2014) }\end{array}$ \\
\hline $\mathrm{Fe}-\mathrm{Mt}$ & $\begin{array}{l}\text { Without } \mathrm{pH} \text { adjustment, } \\
\text { contact time } 20 \mathrm{~min}, \\
\text { sorbent dosage } 4 \mathrm{~g} / \mathrm{L} \text {. }\end{array}$ & 8.85 & $\begin{array}{l}\text { Langmuir adsorption isotherm, } \\
\text { PSO kinetics. }\end{array}$ & $\begin{array}{l}\text { Ren et al. } \\
\quad(2014)\end{array}$ \\
\hline CTMAB-Fe-Mt & $\begin{array}{l}\text { Without } \mathrm{pH} \text { adjustment, } \\
\text { contact time } 20 \mathrm{~min}, \\
\text { sorbent dosage } 4 \mathrm{~g} / \mathrm{L} \text {. }\end{array}$ & 15.15 & $\begin{array}{l}\text { Langmuir adsorption isotherm, } \\
\text { PSO kinetics. }\end{array}$ & $\begin{array}{l}\text { Ren et al. } \\
\quad(2014)\end{array}$ \\
\hline $\mathrm{Fe}-\mathrm{Mt}$ & $\begin{array}{l}\mathrm{pH} 6, \text { contact time } 24 \mathrm{~h}, \\
\text { sorbent dosage } \\
\text { noninformed. }\end{array}$ & 22 & $\begin{array}{l}\text { Adsorption isotherm models and } \\
\text { kinetic analysis were not } \\
\text { considered. As sorption is } \\
\text { enhanced with increasing amounts } \\
\text { of Fe in the modified mineral. }\end{array}$ & $\begin{array}{l}\text { Grygar et al. } \\
\text { (2007) }\end{array}$ \\
\hline Goethite & $\begin{array}{l}\text { Without } \mathrm{pH} \text { adjustment; } \\
\text { contact time } 4 \mathrm{~h}, \\
\text { sorbent dosage } 1.6 \mathrm{~g} / \mathrm{L} \text {. }\end{array}$ & 4 & $\begin{array}{l}\text { Adsorption isotherm models } \\
\text { and kinetic analysis } \\
\text { were not considered. }\end{array}$ & $\begin{array}{l}\text { Lenoble et al. } \\
\quad \text { (2002) }\end{array}$ \\
\hline $\begin{array}{l}\text { Amorphous iron } \\
\text { hydroxide }\end{array}$ & $\begin{array}{l}\text { Without } \mathrm{pH} \text { adjustment; } \\
\text { contact time } 4 \mathrm{~h}, \\
\text { sorbent dosage } 1.6 \mathrm{~g} / \mathrm{L}\end{array}$ & 7 & $\begin{array}{l}\text { Adsorption isotherm models and } \\
\text { kinetic analysis } \\
\text { were not considered. }\end{array}$ & $\begin{array}{l}\text { Lenoble et al. } \\
\quad \text { (2002) }\end{array}$ \\
\hline Pillared Fe-Mt & $\begin{array}{l}\text { Without } \mathrm{pH} \text { adjustment; } \\
\text { contact time } 4 \mathrm{~h}, \\
\text { sorbent dosage } 1.6 \mathrm{~g} / \mathrm{L} \text {. }\end{array}$ & 4 & $\begin{array}{l}\text { Adsorption isotherm models and } \\
\text { kinetic analysis } \\
\text { were not considered. }\end{array}$ & $\begin{array}{l}\text { Lenoble et al. } \\
\text { (2002) }\end{array}$ \\
\hline $\mathrm{Fe}-\mathrm{Mt}$ & $\begin{array}{l}\mathrm{pH} 4.5-9 ; \text { sorbent } \\
\text { dosage } 0.26 \mathrm{~g} / \mathrm{L}\end{array}$ & $\begin{array}{l}3.9 \text { at } \mathrm{pH}=6 \\
1.5 \text { at } \mathrm{pH}=9\end{array}$ & $\begin{array}{l}\text { Adsorption/desorption kinetics } \\
\text { studies. Models } \\
\text { were not applied to data analysis. }\end{array}$ & $\begin{array}{l}\text { Luengo et al. } \\
\text { (2011) }\end{array}$ \\
\hline $\mathrm{Fe}-\mathrm{Mt}$ & $\begin{array}{l}\mathrm{pH}: 8 \text {, contact time } \\
20 \text { min, sorbent } \\
\text { dosage: } 0.5 \mathrm{~g} / \mathrm{L} .\end{array}$ & 6.28 & $\begin{array}{l}\text { Langmuir and Freundlich isotherm } \\
\text { models, PSO kinetics mechanism, } \\
\text { inner-sphere complexes } \\
\text { of As(V) at surface sites. }\end{array}$ & This work \\
\hline
\end{tabular}


or isolated rural areas lacking centralized water supplies. Adsorption-based methods of treatment could be applied along or in combination with oxidation-adsorption-coagulation/flocculation methods. These types of technologies are affordable for low economic income and resource populations due to their ability to work with small-scale equipment and treat small volumes of water to supply small communities or individual houses. Their designs are simple, and their installation and maintenance can be easily handled by the local population (Litter et al., 2012). Nevertheless, the use of these technologies at low or medium scale could have the disadvantage of an inadequate handling and disposal of the generated wastes. In this sense, it is important to have efficient communication during the transference of the technology.

\section{Conclusions}

Montmorillonite was modified in this work with the intercalation of iron oligomers, and it is proposed as an adsorbent material for $\mathrm{As}(\mathrm{V})$ removal from groundwater in small-scale processes. Fe-Mt was synthesized through a lowcost method, and its $\mathrm{As}(\mathrm{V})$ adsorption capacity was evaluated by varying parameters such as $\mathrm{pH}$ or ionic strength.

The iron modification process of montmorillonite led to a basal space expansion as well as a BET surface value and microporosity increment of the material with respect to raw montmorillonite. Moreover, a modification of active surface sites occurred with the deposition of iron oxides. Structure and surface site modification led to Fe-Mt possessing an extraordinary removal power of $\mathrm{As}(\mathrm{V})$ from contaminated water with respect to raw montmorillonite and other adsorbents.

The arsenic adsorption capacity of Fe-Mt had a strong dependence on the physicochemical properties of solutions. Particularly, adsorption capacity was higher at low $\mathrm{pH}$ values; nevertheless, good performance was observed at neutral $\mathrm{pH}$ values. Regarding ionic strength, adsorption capacity increases with $\mathrm{KNO}_{3}$ concentration. This result suggested that Fe-Mt could be appropriate for use in $\mathrm{As}(\mathrm{V})$ removal processes without previous treatment.

Equilibrium adsorption data were successfully fitted to the Langmuir and Freundlich models. A maximum adsorption capacity of $6.3 \mathrm{~g} / \mathrm{kg}$ and a $\mathrm{K}_{\mathrm{L}}$ value of $0.966 \mathrm{~L} / \mathrm{mg}$ were determined by fitting experimental data to the Langmuir model. The time of contact necessary to reach the equilibrium condition was around $20 \mathrm{~min}$. Also, it was determined that the adsorption process followed a PSO law. In addition, the suitable fitting to the IDM and MSR/DCK models indicated that not only a surface reaction controls the rate of the process but a diffusion reaction is also important.

Finally, it was stated that $\mathrm{As}(\mathrm{V})$ reacts with iron surface sites on Fe-Mt through the formation of inner-sphere complexes.

\section{Author Disclosure Statement}

A.I., J.L.M-B., M.A.T, and A.F.C. are members of Consejo Nacional de Investigaciones Científicas y Técnicas (CONICET). All other authors have no competing financial interests.

\section{Funding Information}

The authors gratefully acknowledge the Consejo Nacional de Investigaciones Científicas y Técnicas (CONICET) and the Agencia Nacional de Promoción Científica y Tecnológica (ANPCYT) for the financial support (PICT 2015-1260 and PICT 2015-2010).

\section{Supplementary Material}

Supplementary Data

\section{References}

Alvarez-Cruz, J.L., and Garrido-Hoyos, S.E. (2019). Effect of the mole ratio of $\mathrm{Mn} / \mathrm{Fe}$ composites on arsenic (V) adsorption. Sci. Total Environ. 668, 47.

Ancelet, T., Davy, P.K., Mitchell, T., Trompetter, W.J., Markwitz, A., and Weatherburn, D.C. (2012). Identification of particulate matter sources on an hourly time-scale in a wood burning community. Environ. Sci. Technol. 46, 4767.

Antelo, J., Avena, M., Fiol, S., López, R., and Arce, F. (2005). Effects of $\mathrm{pH}$ and ionic strength on the adsorption of phosphate and arsenate at the goethite-water interface. J. Colloid Interf. Sci. 285, 476.

Apul, D.S., Gardner, K.H., Eighmy, T.T., Fällman, A.M., and Comans, R.N.J. (2005). Simultaneous application of dissolution/precipitation and surface complexation/surface precipitation modeling to contaminant leaching. Environ. Sci. Technol. 39, 5736.

Areco, M.M., Saleh-Medina, L., Trinelli, M.A., Marco-Brown, J.L., and dos Santos Afonso, M. (2013). Adsorption of Cu(II), $\mathrm{Zn}(\mathrm{II}), \mathrm{Cd}(\mathrm{II})$ and $\mathrm{Pb}(\mathrm{II})$ by dead Avena fatua biomass and the effect of these metals on their growth. Colloid. Surface B 110, 305.

Babaee, Y., Mulligan, C.N., and Rahaman, M.S. (2018). Removal of arsenic (III) and arsenic (V) from aqueous solutions through adsorption by $\mathrm{Fe} / \mathrm{Cu}$ nanoparticles. J. Chem. Technol. Biotechnol. 93, 63.

Bee, S.-L., Abdullah, M.A.A., Bee, S.-T., Sin, L.T., and Rahmat, A.R. (2018). Polymer nanocomposites based on silylated-montmorillonite: A review. Prog. Polym. Sci. 85, 57.

Bhattacharyya, K.G., and Gupta, S.S. (2008). Adsorption of a few heavy metals on natural and modified kaolinite and montmorillonite: A review. Adv. Colloid Interfac. 140, 114.

Bhowmick, S., Chakraborty, S., Mondal, P., Van Renterghem, W., Van den Berghe, S., Roman-Ross, G., Chatterjee, D., and Iglesias, M. (2014). Montmorillonite-supported nanoscale zero-valent iron for removal of arsenic from aqueous solution: Kinetics and mechanism. Chem. Eng. J. 243, 14.

Brunauer, S., Emmett, P.H., and Teller, E. (1938). Adsorption of gases in multimolecular layers. J. Am. Chem. Soc. 60, 309.

Bundschuh, J., Litter, M., Ciminelli, V.S.T., Morgada, M.E., Cornejo, L., Hoyos, S.G., Hoinkis, J., Alarcón-Herrera, M.T., Armienta, M.A., and Bhattacharya, P. (2010). Emerging mitigation needs and sustainable options for solving the arsenic problems of rural and isolated urban areas in Latin America-A critical analysis. Water Res. 44, 5828.

Bundschuh, J., Litter, M.I., Parvez, F., Román-Ross, G., Nicolli, H.B., Jean, J.S., Liu, C.W., López, D., Armienta, M.A., Guilherme, L.R.G., Cuevas, A.G., Cornejo, L., Cumbal, L., and Toujaguez, R. (2012). One century of arsenic exposure in Latin America: A review of history and occurrence from 14 countries. Sci. Total Environ. 429, 2.

Chintala, R., Mollinedo, J., Schumacher, T.E., Papiernik, S.K., Malo, D.D., Clay, D.E., Kumar, S., and Gulbrandson, D.W. (2013). Nitrate sorption and desorption in biochars from fast pyrolysis. Microporous Mesoporous Mater. 179, 250. 
Chowdhury, R. (2017). Using adsorption and sulphide precipitation as the principal removal mechanisms of arsenic from a constructed wetland-a critical review. Chem. Ecol. 33, 560.

Chowdhury, R., Apul, D., and Dwyer, D. (2008). Preliminary studies for designing a wetland for arsenic treatment. In L.F. König and J.L. Weiss, Eds., Groundwater: Modeling Management. Hauppage, NY: Nova Science Publishers, Inc., p. 155.

Corroto, C., Iriel, A., Cirelli, A.F., and Carrera, A.L.P. (2019). Constructed wetlands as an alternative for arsenic removal from reverse osmosis effluent. Sci. Total Environ. 691, 1242.

Di Rienzo, J.A., Casanoves, F., Balzarini, M.G., Gonzalez, L., Tablada, M., and Robledo, C.W. (2011). InfoStat. Universidad Nacional de Córdoba. Available at: www.infostat .com.ar (accessed April 2018).

Doğan, M., Abak, H., and Alkan, M. (2009). Adsorption of methylene blue onto hazelnut shell: Kinetics, mechanism and activation parameters. J. Hazard. Mater. 164, 172.

dos Santos Afonso, M., and Stumm, W. (1992). Reductive dissolution of iron(III) (hydr)oxides by hydrogen sulfide. Langmuir 8, 1671.

Essington, M.E. (2004). Soil and Water Chemistry, an Integrative Approach. Boca Raton, FL: CRC Press.

Flores, F.M., Torres Sánchez, R.M., and dos Santos Afonso, M. (2018). Some aspects of the adsorption of glyphosate and its degradation products on montmorillonite. Environ. Sci. Pollut. Res. Int. 25, 18138.

Gil, A., Assis, F.C.C., Albeniz, S., and Korili, S.A. (2011). Removal of dyes from wastewaters by adsorption on pillared clays. Chem. Eng. J. 168, 1032.

Grygar, T., Hradil, D., Bezdička, P., Doušová, B., Čapek, L., and Schneeweiss, O. (2007). Fe(III)-modified montmorillonite and bentonite: Synthesis, chemical and UV-Vis spectral characterization, arsenic sorption, and catalysis of oxidative dehydrogenation of propane. Clay Clay Miner. 55, 165.

Guo, J.Z., Li, B., Liu, L., and Lv, K. (2014). Removal of methylene blue from aqueous solutions by chemically modified bamboo. Chemosphere 111, 225.

Haerifar, M., and Azizian, S. (2013). Mixed surface reaction and diffusion-controlled kinetic model for adsorption at the solid/solution interface. J. Phys. Chem. 117, 8310.

Hayes, K.F., Papelis, C., and Leckie, J.O. (1988). Modeling ionic strength effects on anion adsorption at hydrous oxide/ solution interfaces. J. Colloid Interf. Sci. 125, 717.

He, L.M., Zelazny, L.W., Baligar, V.C., Ritchey, K.D., and Martens, D.C. (1997). Ionic strength effects on sulfate and phosphate adsorption on $\gamma$-alumina and kaolinite: Triple-layer model. Soil Sci. Soc. Am. J. 61, 784.

Higuchi, T., and Connors, K. (1965). Phase solubility techniques. In C.N. Reilley, Ed., Advances in Analytical Chemistry Instrumentation. New York, NY: Interscience, p. 117.

Iriel, A., Dundas, G., Fernández Cirelli, A., and Lagorio, M.G. (2015a). Effect of arsenic on reflectance spectra and chlorophyll fluorescence of aquatic plants. Chemosphere 119, 697.

Iriel, A., Lagorio, M.G., and Fernández Cirelli, A. (2015b). Biosorption of arsenic from groundwater using Vallisneria gigantea plants. Kinetics, equilibrium and photophysical considerations. Chemosphere 138, 383.

Kazi, T.G., Arain, M.B., Baig, J.A., Jamali, M.K., Afridi, H.I., Jalbani, N., Sarfraz, R.A., Shah, A.Q., and Niaz, A. (2009). The correlation of arsenic levels in drinking water with the biological samples of skin disorders. Sci. Total Environ. 407, 1019.

Khoury, G.A., Gehris, T.C., Tribe, L., Torres Sánchez, R.M., and dos Santos Afonso, M. (2010). Glyphosate adsorption on montmorillonite: An experimental and theoretical study of surface complexes. Appl. Clay Sci. 50, 167.

Kumar, A., Gurian, P.L., Bucciarelli-Tieger, R.H., and Mitchell-Blackwood, J. (2008). Iron oxide-Coated fibrous sorbents for arsenic removal. J. Am. Water Works Assoc. 100, 151.

Lenoble, V., Bouras, O., Deluchat, V., Serpaud, B., and Bollinger, J.C. (2002). Arsenic adsorption onto pillared clays and iron oxides. J. Colloid Interf. Sci. 255, 52.

Li, Y., Liu, J.R., Jia, S.Y., Guo, J.W., Zhuo, J., and Na, P. (2012). $\mathrm{TiO}_{2}$ pillared montmorillonite as a photoactive adsorbent of arsenic under UV irradiation. Chem. Eng. J. 191, 66.

Litter, M.I., Alarcón-Herrera, M.T., Arenas, M.J., Armienta, M.A., Avilés, M., Cáceres, R.E., Cipriani, H.N., Cornejo, L., Dias, L.E., Cirelli, A.F., Farfán, E.M., Garrido, S., Lorenzo, L., Morgada, M.E., Olmos-Márquez, M.A., and PérezCarrera, A. (2012). Small-scale and household methods to remove arsenic from water for drinking purposes in Latin America. Sci. Total Environ. 429, 107.

Litter, M.I., Ingallinella, A.M., Olmos, V., Savio, M., Difeo, G., Botto, L., Farfán Torres, E.M., Taylor, S., Frangie, S., Herkovits, J., Schalamuk, I., González, M.J., Berardozzi, E., García Einschlag, F.S., Bhattacharya, P., and Ahmad, A. (2019). Arsenic in Argentina: Occurrence, human health, legislation and determination. Sci. Total Environ. 676, 756.

Liu, G.J., Zhang, X.R., McWilliams, L., Talley, J.W., and Neal, C.R. (2008). Influence of ionic strength, electrolyte type, and $\mathrm{NOM}$ on $\mathrm{As}(\mathrm{V})$ adsorption onto $\mathrm{TiO}_{2}$. J. Environ. Sci. Health A 43, 430.

Luengo, C., Puccia, V., and Avena, M. (2011). Arsenate adsorption and desorption kinetics on a Fe(III)-modified montmorillonite. J. Hazard. Mater. 186, 1713.

Marco-Brown, J.L., Areco, M.M., Torres Sánchez, R.M., and dos Santos Afonso, M. (2014). Adsorption of picloram herbicide on montmorillonite: Kinetic and equilibrium studies. Colloid. Surface A 449, 121.

Marco-Brown, J.L., Barbosa-Lema, C.M., Torres Sánchez, R.M., Mercader, R.C., and dos Santos Afonso, M. (2012). Adsorption of picloram herbicide on iron oxide pillared montmorillonite. Appl. Clay Sci. 58, 25.

Marco-Brown, J.L., Blesa, M.A., and Soler-Illia, G.J.A.A. (2017a). Preparation of mesoporous titania xerogels under controlled synthesis conditions. Effects of processing in the textural, adsorption and photocatalytic properties. Colloid. Surface A 530, 93.

Marco-Brown, J.L., Gaigneaux, E.M., Torres Sánchez, R.M., and dos Santos Afonso, M. (2019). Adsorption of picloram on clays nontronite, illite and kaolinite: Equilibrium and herbicide-clays surface complexes. J. Environ. Sci. Health A $54,1$.

Marco-Brown, J.L., Guz, L., Olivelli, M.S., Schampera, B., Torres Sánchez, R.M., Curutchet, G., and Candal, R. (2018). New insights on crystal violet dye adsorption on montmorillonite: Kinetics and surface complexes studies. Chem. Eng. J. 333, 495.

Marco-Brown, J.L., Trinelli, M.A., Gaigneaux, E.M., Torres Sánchez, R.M., and Dos Santos Afonso, M. (2015). New insights on the structure of the picloram-montmorillonite surface complexes. J. Colloid Interf. Sci. 444, 115.

Marco-Brown, J.L., Undabeytia, T., Torres Sánchez, R.M., and dos Santos Afonso, M. (2017b). Slow-release formulations of the herbicide picloram by using $\mathrm{Fe}-\mathrm{Al}$ pillared montmorillonite. Environ. Sci. Pollut. Res. Int. 24, 10410. 
Mohan, D., and Pittman, C.U., Jr. (2007). Arsenic removal from water/wastewater using adsorbents-A critical review. $J$. Hazard. Mater. 142, 1.

Murcott, S. (2012). Arsenic Contamination in the World: An International Sourcebook. London: IWA Publishing.

Partey, F., Norman, D.I., Ndur, S., and Nartey, R. (2009). Mechanism of arsenic sorption onto laterite iron concretions. Colloid. Surface A 337, 164.

Peng, X., Hu, F., Huang, J., Wang, Y., Dai, H., and Liu, Z. (2016). Preparation of a graphitic ordered mesoporous carbon and its application in sorption of ciprofloxacin: Kinetics, isotherm, adsorption mechanisms studies. Microporous Mesoporous Mater. 228, 196.

Reeve, N.G., and Sumner, M.E. (1971). Cation exchange capacity and exchangeable aluminum in natal oxisols. Soil Sci. Soc. Am. Proc. 35, 38.

Ren, X., Zhang, Z., Luo, H., Hu, B., Dang, Z., Yang, C., and Li, L. (2014). Adsorption of arsenic on modified montmorillonite. Appl. Clay Sci. 97-98, 17.

Rietveld, H. (1969). A profile refinement method for nuclear and magnetic structures. J. Appl. Crystallogr. 2, 65.

Sherlala, A.I.A., Raman, A.A.A., Bello, M.M., and Buthiyappan, A. (2019). Adsorption of arsenic using chitosan magnetic graphene oxide nanocomposite. J. Environ. Manage. 246, 547.

Siguín, D., Ferreira, S., Froufe, L., and García, F. (1994). Smectites: The relationship between their properties and isomorphic substitution. J. Mater. Sci. 29, 4379.

Sinha, D., Dey, S., Bhattacharya, R.K., and Roy, M. (2007). In vitro mitigation of arsenic toxicity by tea polyphenols in human lymphocytes. J. Environ. Pathol. Toxicol. Oncol. 26, 207.

Smedley, P.L., and Kinniburgh, D.G. (2002). A review of the source, behaviour and distribution of arsenic in natural waters. Appl. Geochem. 17, 517.

Smedley, P.L., Kinniburgh, D.G., Macdonald, D.M.J., Nicolli, H.B., Barros, A.J., Tullio, J.O., Pearce, J.M., and Alonso, M.S. (2005). Arsenic associations in sediments from the loess aquifer of La Pampa, Argentina. Appl. Geochem. 20, 989.
Stumm, W. (1992). Chemistry of the Solid Water Interface. Processes at the Mineral-Water and Particle-Water Interface in Natural Systems, 1st ed. New York: Wiley \& Sons.

Sun, Q., and Yang, L. (2003). The adsorption of basic dyes from aqueous solution on modified peat-resin particle. Water Res. 37, 1535.

Timofeeva, M.N., Khankhasaeva, S.T., Chesalov, Y.A., Tsybulya, S.V., Panchenko, V.N., and Dashinamzhilova, E.T. (2009). Synthesis of Fe,Al-pillared clays starting from the Al,Fe-polymeric precursor: Effect of synthesis parameters on textural and catalytic properties. Appl. Catal. B Environ. 88, 127.

Tombácz, E., Csanaky, C., and Illés, E. (2001). Polydisperse fractal aggregate formation in clay mineral and iron oxide suspensions, $\mathrm{pH}$ and ionic strength dependence. Colloid. Polym. Sci. 279, 484.

Tschapek, M., Sanchez, R.M.T., and Wasowski, C. (1989). Handy methods for determining the isoelectric point of soils. Z. Pflanz. Bodenkunde. 152, 73.

Wang, Y., Zeng, X., Lu, Y., Bai, L., Su, S., and Wu, C. (2017). Dynamic arsenic aging processes and their mechanisms in nine types of Chinese soils. Chemosphere 187, 404.

Wang, Z., Hu, W., Kang, Z., He, X., Cai, Z., and Deng, B. (2019). Arsenate adsorption on iron-impregnated ordered mesoporous carbon: Fast kinetics and mass transfer evaluation. Chem. Eng. J. 357, 463.

Xu, F., Chen, H., Dai, Y., Wu, S., and Tang, X. (2019). Arsenic adsorption and removal by a new starch stabilized ferromanganese binary oxide in water. J. Environ. Manage. 245, 160.

Xu, R., Jiang, J., and Cheng, C. (2010). Effect of ionic strength on specific adsorption of ions by variable charge soils: experimental testification on the adsorption model of Bowden et al. In J. Xu and P.M. Huang, P.M., Eds., Molecular Environmental Soil Science at the Interfaces in the Earth's Critical Zone. Berlin, Heidelberg: Springer Berlin Heidelberg, p. 78.

Zhu, R., Chen, Q., Zhou, Q., Xi, Y., Zhu, J., and He, H. (2016). Adsorbents based on montmorillonite for contaminant removal from water: A review. Appl. Clay Sci. 123, 239. 